\title{
In the era of broad spectrum antibiotics, is ampicillin still an option?
}

\author{
Cristina Popescu ${ }^{1,2^{*}}$, Gabriel-Adrian Popescu ${ }^{1,2}$, Alina Lobodan ${ }^{1}$, Raluca Dulama ${ }^{1}$, Doina Niculescu ${ }^{1}$, Diana Tănase ${ }^{1}$, \\ Mihaela Rădulescu ${ }^{1,2}$, Violeta Molagic ${ }^{1}$, Cătălin Tilişcann ${ }^{1,2}$, Liliana Ion', Mirela Cernat ${ }^{1}$, Mirela Dinu', lulia Caragea ${ }^{1}$, \\ Angelica Teniță', Georgiana Juganaru', Elisabeta Benea ${ }^{1,2}$, Victoria Aramă ${ }^{1,2}$
}

From The 9th Edition of the Scientific Days of the National Institute for Infectious Diseases Prof Dr Matei Bals Bucharest, Romania. 23-25 October 2013

\section{Background}

In the era of broad spectrum antibiotics it is sometimes difficult to choose the best antimicrobial regimens. Because of misuse and abuse of antimicrobial usage, the level of resistance is increasing and sometimes we do not have treatment options. Infectious diseases specialists traditionally have the leadership role in optimal use of antimicrobials. Antimicrobial stewardship represents a worldwide accepted concept in order to preserve currently available antibiotics.

\section{Case report}

We present 4 cases of severe sepsis with known etiology successfully treated with ampicillin. The first patient was diagnosed with enterococcal spondylodiscitis related to colon diverticulitis. The second patient was a pregnant woman who developed listeriosis. The third patient was diagnosed with pneumococcal meningitis and the forth patient was diagnosed with bacteremic pneumococcal pneumonia. We chose ampicillin because of its narrow antimicrobial spectrum, among therapeutic alternatives. A cost efficiency analysis was performed for each patient.

\section{Conclusion}

We emphasize the importance of microbiological diagnosis in order to use de-escalation. Ampicillin remains a very good option in severe infections produced by sensitive germs.

\footnotetext{
* Correspondence: crispopescu3@yahoo.com

${ }^{1}$ National Institute for Infectious Diseases "Prof. Dr. Matei Balş", Bucharest, Romania

Full list of author information is available at the end of the article
}

\section{Authors' details}

${ }^{1}$ National Institute for Infectious Diseases "Prof. Dr. Matei Balş", Bucharest, Romania. ${ }^{2}$ Carol Davila University of Medicine and Pharmacy, Bucharest, Romania.

Published: 16 December 2013

doi:10.1186/1471-2334-13-S1-014

Cite this article as: Popescu et al:: In the era of broad spectrum antibiotics, is ampicillin still an option? BMC Infectious Diseases 2013 13(Suppl 1):014.
Submit your next manuscript to BioMed Central and take full advantage of:

- Convenient online submission

- Thorough peer review

- No space constraints or color figure charges

- Immediate publication on acceptance

- Inclusion in PubMed, CAS, Scopus and Google Scholar

- Research which is freely available for redistribution

Submit your manuscript at www.biomedcentral.com/submit
C Bïomed Central

\section{Biomed Central}

